\title{
Factual text and emotional pictures: overcoming a false dichotomy of cigarette warning labels
}

\author{
Lucy Popova, ${ }^{1}$ Daniel Owusu, ${ }^{2}$ Desmond Jenson, ${ }^{3}$ Torsten B Neilands ${ }^{4}$
}

- Additional material is published online only. To view please visit the journal online (http://dx.doi.org/10.1136/ tobaccocontrol-2016-053563).

${ }^{1}$ School of Public Health, Georgia State University, Atlanta, Georgia, USA ${ }^{2}$ School of Public Health, Georgia State University, Atlanta, Georgia, USA ${ }^{3}$ Tobacco Control Legal Consortium, a program of the Public Health Law Center, at the Mitchell Hamline School of Law, Saint Paul, Minnesota, USA ${ }^{4}$ Department of Medicine, University of California San Francisco, San Francisco, California, USA

\section{Correspondence to}

Dr Lucy Popova, School of Public Health, Georgia State University, P.O. Box 3995, Atlanta, GA 30302, USA:

Ipopova1@gsu.edu

Received 29 November 2016 Revised 15 March 2017 Accepted 17 March 2017 Published Online First 20 April 2017
Check for updates

To cite: Popova L, Owusu D, Jenson $\mathrm{D}$, et al. Tob Control 2018:27:250-253.

\section{ABSTRACT}

Background In reviewing the first set of pictorial warning labels in the USA, the courts equated textual labels with facts and information, and images with emotion. This study tested the differences in perceived informativeness and emotion between textual and pictorial cigarette warning labels.

Methods An online study with 1838 US adults who were non-smokers $(n=764)$, transitioning smokers (quit smoking in the past 2 years or currently trying to quit, $n=505)$ or current smokers $(n=569)$. Each participant evaluated 9 out of 81 text and pictorial cigarette warning labels. Participants reported to what extent they perceived the label as informative and factual and the negative emotions they felt while looking at each label. We used linear mixed models to account for the nesting of multiple observations within each participant.

Results There were no significant differences in perceived informativeness between textual (mean 6.15 on a 9-point scale) and pictorial labels (6.14, $p=0.80$, Cohen's $d=0.003)$. Textual labels evoked slightly less emotion (4.21 on a 9-point scale) than pictorial labels (4.42, $p<0.001$, Cohen's $d=0.08)$. Perceived informativeness and emotion were strongly correlated (Pearson $r=0.53, p<0.001$ ).

Conclusion Our findings contradict courts' conclusions that pictorial messages are emotional and not factual. Pictorial labels are rated as informative and factual, textual labels evoke emotion, and emotionality and informativeness are strongly correlated. These findings serve as evidence for the Food and Drug Administration (FDA) to counteract the claim that pictorial warning labels, by definition, are not 'purely factual and uncontroversial'.

\section{INTRODUCTION}

Every year, tobacco causes over 6 million preventable deaths worldwide. ${ }^{1}$ To reduce this toll, countries have implemented regulations, such as taxation, restrictions on sales and advertising, and health warnings on tobacco products. Warnings on cigarette packs have evolved from non-specific text statements to pictorial warnings covering most of the pack surface. ${ }^{23}$ As of 2016 , at least 105 countries/jurisdictions finalised regulations requiring pictorial warnings on cigarettes. ${ }^{4}$

In the USA, cigarette packs carry textual warnings that remain unchanged since 1984. Because the warnings had grown stale and were no longer effective, the US Food and Drug Administration (FDA) developed nine pictorial warning labels for cigarette packages and advertisements, as mandated by the US Congress. ${ }^{56}$
In response, tobacco companies filed two separate judicial challenges, ${ }^{78}$ arguing that the pictorial warnings violated the companies' First Amendment (free speech) rights. The two lawsuits had different outcomes due to the application of two different legal standards. In the first case (Discount Tobacco), the tobacco industry challenged the FDA's mandate to institute new warnings. The court applied the standard established in Zauderer ${ }^{9}$ where the compelled speech at issue must be found to be factual and uncontroversial and reasonably related to a legitimate government interest. The courts in that case upheld the provision requiring pictorial warning labels, finding the requirement constitutional. $^{7}$

In the second case (RJ Reynolds), the tobacco industry challenged the specific pictorial warnings that were developed by the FDA. The court in $R J$ Reynolds used the more stringent Central Hudson ${ }^{10}$ test, in part, because it found that 'the graphic warnings do not constitute the type of 'purely factual and uncontroversial' information, ... to which the Zauderer standard may be applied'. ${ }^{8}$ The courts decided that those nine pictorial warnings were unconstitutional under the more strict standard. ${ }^{8}$

The courts never explicitly defined 'factual and uncontroversial' speech, but alluded that it is an antithesis to emotional speech. ${ }^{11}$ In both lawsuits, the courts distinguished between textual and pictorial messages, equating the first with facts and the latter with emotion. For example, the court stated, 'As a threshold matter, there is no indication that the textual element of the new warning labels, when viewed in isolation, express either completely 'subjective' or 'highly controversial' messages.' Yet 'in contrast to the textual warnings, there can be no doubt that the FDA's choice of visual images is subjective, and that graphic, full-colour images, because of the inherently persuasive character of the visual medium, cannot be presumed neutral'.?

However, textual warnings do evoke emotions ${ }^{1213}$ and pictorial labels can be informative and factual. ${ }^{14}$ Some studies found that pictorial warnings cause greater levels of negative emotions, ${ }^{15}$ but few US studies examined whether consumers perceive pictorial warnings as factual ${ }^{16}$ and to what extent the two perceptions are related..$^{17}$ This study tests the differences in respondents' perceptions of textual and pictorial warnings on cigarettes and begins to fill these gaps.

\section{METHODS \\ Materials}

This study used 81 textual and pictorial warning labels. It included the nine pictorial warnings proposed by the FDA, in three versions: the labels 
with both text and picture, the text only version and a version that had only the picture with warning text removed. Additional 27 text and 27 pictorial labels were developed based on labels used in other countries and antitobacco messages. All the labels are provided in the online supplementary appendix.

\section{Participants}

Participants were recruited by a survey market research company (www.toluna-group.com). The sample included adults aged $18+$ years who were never-smokers (have not smoked 100 cigarettes in their lifetime, $n=764$ ), current smokers (smoked at least 100 cigarettes and were currently smoking every day or some days and not currently trying to quit, $n=569$ ) or transitioning smokers (having quit within the past 2 years or currently trying to quit, $\mathrm{n}=505$ ). All participants completed electronic informed consent; all protocols were approved by the University of California, San Francisco IRB. Data collection period was 30 days.

\section{Procedure}

We conducted a pilot test with 104 participants to examine feasibility, refine the questionnaire and determine the number of messages for evaluation. Past studies used between 1 and 64 labels (mean $=6$ ). ${ }^{15}$ On the basis of the pilot, participants were able to evaluate nine messages without fatigue; median time for the study was $19 \mathrm{~min}$.

In the main study, participants saw nine labels each. The selection and order of labels was determined by a randomised incomplete blocks design (using SAS PROC PLAN) to randomly order presentation of 3 FDA labels (one each from the categories: text and picture, text only and picture only) and to select 3 each of 27 possible non-FDA text labels and 3 each of 27 possible non-FDA pictorial labels. Participants saw labels one at a time on the unbranded cigarette pack (see online supplementary appendix). Participants viewed each label without time constraint but could not return to previous labels. After seeing each label, participants answered questions (in random order) about their perceptions of the label.

Median study time was $20 \mathrm{~min}$. At the end, all participants saw a debriefing page stating that the warnings they might have seen were used for research only, are not currently in use and have not been approved by the FDA. After completing the study, all participants were provided a quitline telephone number and smoking cessation website addresses.

\section{Measures}

Participants answered to what extent the label was informative, gave them a better understanding of the consequences of smoking, was based on facts, presented something that happened in real life and portrayed an actual risk of smoking ${ }^{18-20}$ (perceived informativeness scale, $\alpha=0.93$ ). Participants rated to what extent they felt negative emotions (sad, angry, afraid, guilty, disgusted and worried) ${ }^{12}{ }^{21}$ while looking at each label (emotion scale, $\alpha=0.93$ ). All items were on a 1 (not at all) to 9 (extremely) rating scale.

We also measured sex, age, race and education (see table 1 for these variables' operationalisations). We asked smokers how many cigarettes per day they smoke on average.

\section{Data analysis}

We first conducted descriptive analysis to estimate the proportions of participants in the categories of independent variables. We used PROC MIXED to obtain means of perceived informativeness and emotion for both text and pictorial labels, adjusting for covariates. Secondary analyses compared the three versions of the nine FDA labels (text only, picture only and text+picture). For each outcome (perceived informativeness, emotion), four models were built: (1) all participants combined, (2) never smokers, (3) transitioning smokers and (4) current smokers. In each model, label type (text or pictorial), age, sex, race and educational level were included as fixed effects. In the combined model, smoking status was also included as a fixed effect, whereas the number of cigarettes smoked daily was included as a fixed effect in the current smokers model. To account for the clustering of observations within participants, participant ID was included as the random effect variable using the RANDOM INTERCEPT statement. The LSMEANS statement was used to compute least squares means which are adjusted or marginal means. The CL option provided 95\% CIs for the estimates and the DIFF option was used to compare the estimated means. Cohen's $d$ was then computed as the unadjusted sample mean differences of text and pictorial labels divided by the corresponding pooled SD. For the purpose of statistical inferences, $\mathrm{p}<0.05$ was considered significant in all estimates. All analyses were conducted using SAS V.9.4.

\section{RESULTS}

The sample was $62 \%$ female, $68 \%$ white, $45 \%$ college graduates, with a mean age of 47 .

\begin{tabular}{|c|c|c|c|c|c|}
\hline & Pictorial Labels (LSM, CI) & Text Labels (LSM, CI) & LSM Diff t-value & $p$-value & Cohen's $d$ \\
\hline \multicolumn{6}{|l|}{ Perceived Informativeness } \\
\hline Overall $(n=1838)$ & 6.14 (6.02 to 6.27$)$ & 6.15 (6.02 to 6.27$)$ & 0.25 & 0.80 & 0.003 \\
\hline Never smoker $(n=764)$ & $6.13(5.96$ to 6.31$)$ & 6.16 (5.99 to 6.34$)$ & 0.77 & 0.44 & 0.01 \\
\hline Transitioning smoker $(n=505)$ & 6.42 (6.17 to 6.68$)$ & 6.39 (6.13 to 6.64$)$ & -0.77 & 0.44 & 0.01 \\
\hline Current smoker ( $n=569$ ) & 5.89 (5.67 to 6.11$)$ & 5.90 (5.67 to 6.13 ) & 0.30 & 0.76 & 0.01 \\
\hline \multicolumn{6}{|l|}{ Emotion } \\
\hline Overall & 4.42 (4.28 to 4.56$)$ & 4.21 (4.07 to 4.35$)$ & -11.55 & $<0.001$ & 0.08 \\
\hline Never smoker & 3.63 (3.45 to 3.83$)$ & 3.40 (3.21 to 3.59$)$ & -8.90 & $<0.001$ & 0.10 \\
\hline Transitioning smoker & 5.06 (4.74 to 5.37$)$ & 4.82 (4.51 to 5.13 ) & -6.04 & $<0.001$ & 0.05 \\
\hline Current smoker & 4.54 (4.27 to 4.80$)$ & 4.38 (4.11 to 4.65$)$ & -4.91 & $<0.001$ & 0.06 \\
\hline
\end{tabular}

Estimates are from PROC MIXED models in SAS.

All estimates were adjusted for sex (men vs women), age (<25 years, 25-44 years, 45-64 years and 65+ years), race (white vs other races) and educational level (high school or less, some college and Bachelor's degree or higher).

Smoking status was adjusted for in the overall estimates. In the estimates for current smokers, number of cigarettes smoked daily was also adjusted for. Cohen's d was computed as differences in sample means divided by the corresponding pooled SD.

LSM, least squares means; LSM Diff, differences of least squares means. 
Table 2 Differences in perceived informativeness and emotion between three versions of the nine Food and Drug Administration (FDA) labels (text only, picture only and text+picture)

\begin{tabular}{lllllll}
\hline & FDA text only (LSM, CI) & FDA picture only (LSM, CI) & $\begin{array}{l}\text { FDA text+picture } \\
\text { (LSM, CI) }\end{array}$ & $\begin{array}{l}\text { Overall } \\
\text { p-value }\end{array}$ & $\begin{array}{l}\text { Cohen's } \mathbf{d} \\
\text { (T vs P) }\end{array}$ & $\begin{array}{l}\text { Cohen's d (T Cohen's d } \\
\text { vs TP) }\end{array}$ \\
\hline (P vs TP)
\end{tabular}

Estimates are from PROC MIXED models in SAS. All estimates were adjusted for sex, age, race and educational level. Smoking status was adjusted for in the overall estimates. In the estimates for current smokers, number of cigarettes smoked daily was also adjusted for. Overall p-values were from the Type 3 F-tests of Fixed Effects from SAS PROC MIXED. Estimates with the different superscripts in each row are significantly different $(p<0.05)$. Cohen's $d$ was computed as differences in sample means divided by corresponding pooled SD.

LSM, least squares means; LSM Diff, differences of least squares Means; P, picture only; T, text only; TP, text + picture.

Textual and pictorial labels did not differ significantly in perceived informativeness (table 1), overall or when we stratified by smoking status. There was no significant interaction between type of the label and smoking group $(F(2,14,701)=0.63$, $\mathrm{p}=0.53$ ).

Pictorial warnings evoked higher levels of emotion than textual warnings (overall and stratified by smoking status, table 1 ). The interaction between the type of the label and smoking group was not significant $(F(2,14,701)=1.87, \mathrm{p}=0.16)$.

Secondary analyses compared the three versions of the nine FDA labels (table 2). Text only and text + picture did not differ in perceived informativeness and were significantly higher than the picture only version. For emotion, text only was lowest, followed by picture only, and text+ picture was the highest.

There were significant positive correlations between perceived informativeness and emotion, ranging from Pearson $\mathrm{r}=0.42$ (never smokers) to $\mathrm{r}=0.67$ (current smokers), with overall $\mathrm{r}=0.53$, a large effect size (all $\mathrm{p}<0.001){ }^{22}$ The correlations were significant when examined separately by text and pictorial labels, and by smoking group.

\section{DISCUSSION}

The US courts interpreted textual warnings on cigarettes as factual information and pictorial warnings as 'unabashed attempts to evoke emotion', implying a dichotomy between facts and emotion. ${ }^{78}$ Several legal scholars criticised the court's decision that emotional pictures should not be allowed as informative disclosures. ${ }^{172324}$ This article provides empirical evidence that further challenges the courts' conclusion.

This study found that current smokers, transitioning smokers, and never smokers all perceive pictorial warning labels as informative and factual. They gave the same ratings to pictorial and textual labels in terms of being informative, based on facts, and portraying real consequences of smoking. On average, both textual and pictorial warnings were rated above 6 on the 9-point scale for informativeness, indicating that participants thought them to be relatively highly informational and factual. Thus, although court judges differentiate between textual and pictorial labels in terms of factuality, respondents do not perceive this distinction.

Textual labels evoked lower levels of emotion than pictorial labels, but the differences in the levels of emotion were in the very small to small range according to Cohen's classification. ${ }^{22}$ Furthermore, the average levels of reported negative emotion were around 4 , below the midpoint of the 9-point scale, possibly indicating that even these ostensibly emotional labels do not evoke as much emotion as judges presume. It is possible that this relatively low level of emotion was due to respondents being desensitised by the vivid portrayals of health consequences of smoking (such as from the CDC's campaign Tips from Former Smokers ${ }^{25}$ ). Future studies could evaluate whether people with more exposure to antitobacco campaigns report lower levels of emotion.

Non-smokers reported lower emotional responses than smokers; these messages were probably less relevant to them because they do not smoke. If emotion is the mechanism through which these messages work, ${ }^{26-28}$ then these messages would have greater impact on current and transitioning smokers-exactly the audience the warnings are intending to reach.

This study is the first to demonstrate a strong significant positive association between how factual and informative a label was perceived and how much emotion it aroused. This further challenges the definition of 'factual' speech as 'non-emotional' stimuli. ${ }^{11}$

This cross-sectional study is limited by one-time exposure, making it impossible to evaluate whether emotions or perceptions of factuality come first. This study focused on perceptions and left the evaluation of the effects of various perceptions on outcomes (eg, attention, behavioural intentions or behaviour) to future research. Although the study sample was drawn from a diverse sample of US adults with heterogeneous demographics, it was a non-probability-based sample with more women and older participants than the average US census figures; this limits the generalisability of the findings.

In conclusion, tobacco companies used litigation to stop the implementation of pictorial warnings in the USA, an intervention that has been shown effective in other countries. ${ }^{29-32}$ Organisations working on reducing tobacco-related death and disease have also recently resorted to litigation. In October 2016, public health and medical groups filed a lawsuit to compel the FDA to fulfil its mandate to implement pictorial warnings on cigarettes. ${ }^{33}$ This lawsuit might restart the regulatory process on pictorial warnings. In defending the next set of warning labels, the FDA may argue that any communication of information about health 
consequences of tobacco is, by its nature, emotional, but that such a finding should not render a warning any less factual or uncontroversial. As Tushnet wrote, 'The government may be required to be neutral [...] It is not required to be neutered. When the government can otherwise constitutionally mandate disclosure, the fact that these disclosures have emotional resonance is not an independent constitutional barrier. ${ }^{23}$

\section{What this paper adds}

- In striking down the pictorial warning labels on cigarettes put forth by the Food and Drug Administration (FDA), the court ruled that because pictorial labels are inherently emotional, they are not 'purely factual', essentially creating a dichotomy equating textual labels with facts and information and pictorial warnings with emotion.

- This study demonstrated that in contrast to the court's assertion, respondents in the USA perceive both textual and pictorial labels as factual and informational. Both textual and pictorial labels evoke emotion, and the informativeness and emotionality of warning labels are highly correlated.

Acknowledgements The authors wish to thank Jono Polansky of OnBeyond LLC for help with developing the labels.

Contributors LP conceptualized the study, developed the materials and wrote the first draft. TBN determined the algorithm for assigning labels to participants and advised on the data analysis. DO conducted the statistical analyses. DJ contributed to writing the implications. All authors contributed to the writing and revision and approved the final version of the manuscript.

Funding Research reported in this publication was supported by the National Cancer Institute of the National Institutes of Health and the Food and Drug Administration, Center for Tobacco Products (R00CA187460), National Institute of Drug Abuse of the National Institutes of Health and Food and Drug Administration, Center for Tobacco Products (P50DA036128), and the Robert Wood Johnson Foundation. The content is solely the responsibility of the authors and does not necessarily represent the official views of the National Institutes of Health or the Food and Drug Administration or the Robert Wood Johnson Foundation.

Competing interests None declared.

Ethics approval IRB at the University of California San Francisco.

Provenance and peer review Not commissioned; externally peer reviewed.

(c) Article author(s) (or their employer(s) unless otherwise stated in the text of the article) 2018. All rights reserved. No commercial use is permitted unless otherwise expressly granted.

\section{REFERENCES}

1 World Health Organization. Tobacco 2016. http://www.who.int/mediacentre/ factsheets/fs339/en/ (accessed 8 Oct 2016).

2 Hiilamo H, Crosbie E, Glantz SA. The evolution of health warning labels on cigarette packs: the role of precedents, and tobacco industry strategies to block diffusion. Tob Control 2014;23:e2

3 Chapman S. "Avoid health warnings on all tobacco products for just as long as we can": a history of Australian tobacco industry efforts to avoid, delay and dilute health warnings on cigarettes. Tob Control 2003;12:iii13-iii22.
4 Canadian Cancer Society. 2016. Cigarette Package Health Warnings: International Status Report http://www.tobaccolabels.ca/healthwarningsinfo/statusreport/ (accessed 30 Oct 2016).

5 Family Smoking Prevention and Tobacco Control and Federal Retirement Reform. 2009; http://www.gpo.gov/fdsys/pkg/PLAW-111 publ31/pdf/PLAW-111 publ31.pdf. Public Law 111-31, US Statutes at Large 123: 1776

6 H.R. REP. NO. 111-58, pt. 1, at 4(2009), reprinted in 2009 U.S.C.C.A.N. 468, 471.

7 Disc.Tobacco City \& Lottery, Inc. v. United States, 674 F.3d 509, 518 (6th Cir. 2012).

8 R.J. Reynolds Tobacco Co. v. FDA, 696 F.3d1205 (D.C. Cir. 2012).

9 Zauderer v. Office of Disciplinary Counsel,471 U.S. 626 (1985).

10 Central Hudson Gas \& Electric Corp. v. Public Service Commission, 447 US 557 (1980).

11 Peters E, Evans AT, Hemmerich N, et al. Emotion in the law and the lab: the case of graphic cigarette warnings. Tob Regul Sci 2016;2:404-13.

12 Nonnemaker J, Farrelly MC, Kamyab K, et al. Experimental study of graphic cigarette warning labels: final results report prepared for Center for Tobacco Products, Food and Drug Administration. 2010

13 Rosselli F, Skelly JJ, Mackie DM. Processing rational and emotional messages: the cognitive and affective mediation of persuasion. J Exp Soc Psychol 1995;31:163-90.

14 Lipkus IM, Hollands JG. The visual communication of risk. J Natl Cancer Inst Monogr 1999;25:149-63.

15 Noar SM, Hall MG, Francis DB, et al. Pictorial cigarette pack warnings: a meta-analysis of experimental studies. Tob Control 2016;25.

16 Peters E, Romer D, Slovic P, et al. The impact and acceptability of Canadian-style cigarette warning labels among U.S. smokers and nonsmokers. Nicotine Tob Res 2007:9:473-81.

17 Jolls C. Debiasing through law and the First Amendment. Stan L Rev 2015;67:1411.

$18 \mathrm{Cho} \mathrm{H}$, Shen L, Wilson K. Perceived realism: dimensions and roles in narrative persuasion. Commun Res 2014;41:828-51.

19 Magnan RE, Cameron LD. Do young adults perceive that cigarette graphic warnings provide new knowledge about the harms of smoking? Ann Behav Med 2015:49:594-604.

20 Teigen KH. Perceived informativeness of verbal information. Curr Psychol 1985:4:3-16.

21 Popova L, So J, Sangalang A, et al. Do emotions spark interest in alternative tobacco products? Health Educa Behav 2017;95

22 Cohen J. Statistical power analysis for the behavioral sciences. Hillsdale, New Jersey: Lawrence Erlbaum Associates, 1987.

23 Tushnet R. More than a feeling: emotion and the First Amendment. Harv Law Rev 2014;127.

24 O'Donovan K. Smoke and mirrors: preventing deception of consumers in the tobacco market through graphic warning labels. Alb Gov't L Rev 2014;7:291.

25 Centers for Disease Control and Prevention. Tips from former smokers. $2016 \mathrm{http}: / /$ www.cdc.gov/tobacco/campaign/tips/ (accessed 17 Feb 2016).

26 Wang AL, Lowen SB, Romer $\mathrm{D}$, et al. Emotional reaction facilitates the brain and behavioural impact of graphic cigarette warning labels in smokers. Tob Control 2015;24:225-32

27 Byrne S, Katz SJ, Mathios A, et al. Do the ends justify the means? A test of alternatives to the FDA proposed cigarette warning labels. Health Commun 2015;30:680-93.

28 Evans AT, Peters E, Shoben A, et al. Cigarette graphic warning labels are not created equal: they can increase or decrease smokers' quit intentions relative to text-only warnings. Nicotine Tob Res 2016:ntw389.

29 Hammond D, Fong GT, McDonald PW, et al. Impact of the graphic Canadian warning labels on adult smoking behaviour. Tob Control 2003;12:391-5.

30 Hammond D, Fong GT, McNeill A, et al. Effectiveness of cigarette warning labels in informing smokers about the risks of smoking: findings from the international tobacco control (ITC) four country survey. Tob Control 2006;15(Suppl 3):iii19-iii25.

31 Noar SM, Francis DB, Bridges C, et al. The impact of strengthening cigarette pack warnings: systematic review of longitudinal observational studies. Soc Sci Med 2016;164:118-29

32 Hammond D. Health warning messages on tobacco products: a review. Tob Control 2011:20:327-37.

33 Campaign for Tobacco-Free Kids. 8 health groups file suit to force FDA to require graphic cigarette warnings as mandated by law. $2016 \mathrm{http}: / / w w w . t o b a c c o f r e e k i d s$. org/press_releases/post/2016_10_04_fda (accessed 11 Nov 2016). 